\title{
The Multilingual Assessment Instrument for Narratives: Greek
}

\author{
Ianthi Maria Tsimpli \\ University of Cambridge
}

\author{
Maria Andreou \\ University of Cologne
}

Eleni Peristeri

University of Thessaly

This paper presents an overview of the adaptation of the Multilingual Assessment Instrument for Narratives in Greek, focusing on its use in Greek academic and diagnostic settings. A summary of the properties of the Greek language and the concomitant challenges these language-specific properties posed to MAIN adaptation are presented along with a summary of published studies with monolingual Greek-speaking children and bilingual children with Greek as L2, with and without Developmental Language Disorder.

\section{Introduction}

Children's story telling is a social and educational practice that is common in the Greek society especially during the preschool and early school years. The Greek curriculum treats narration and story-telling as a child-centered activity, principally aimed at boosting children's literacy and social development (Beazidou, Botsoglou, \& Vlachou, 2013). Furthermore, in the last decade, the Greek Ministry of Education has highlighted the importance of using narratives for the clinical diagnosis of children with neurodevelopmental disorders, including Developmental Language Disorder (DLD) and Autism Spectrum Disorder (Botsas, 2017). Though the need to include narrative tests in the assessment of Greek-speaking children with language delays and design large-scale training courses for professionals, who work in the field of special education, has been emphasized by both governmental and private authorities, narrative assessment tools 
specifically designed to assess the language performance of children who are native or nonnative speakers of Greek, are currently lacking. Within this context, the Multilingual Assessment Instrument for Narratives (Language Impairment Testing in Multilingual Settings LITMUS-MAIN, hereafter MAIN; Gagarina et al., 2012, 2015, 2019) and its Greek version represents a notable exception of a valid and reliable narrative assessment measure that can be used to elicit telling and retelling data, and also involves a comprehension element. So far, the MAIN has been used to test the narrative abilities of Greek-speaking monolingual children, as well as bilingual children speaking Greek as a second language (L2), with or without DLD. The first Greek adaptation of MAIN was carried out at the Language Development Lab of the Department of Theoretical and Applied Linguistics at the Aristotle University of Thessaloniki by the authors of this paper, Ianthi Tsimpli (Director of the Lab), Maria Andreou and Eleni Peristeri (research associates).

\section{$2 \quad$ An overview of Greek}

Greek is a typical null-subject language with rich person and number agreement marking on verbs. As a null subject language, null subjects are the preferred option when topic continuity of a referent is established. Overt DP subjects can appear in preverbal or postverbal position with word-order variations including VSO and VOS in addition to SVO. Greek verbs are also inflected for tense (+/-past), aspect (+/-perfective) and voice marking (active/non-active). The nominal domain is also highly inflectional. Nouns, adjectives, determiners and pronouns all exhibit morphological marking for several inflectional features. Specifically, Greek nouns inflect for number (+/-plural), gender (masculine, feminine and neuter) and case (nominative, genitive, accusative) marked on the noun's ending. Gender, number and case are also marked on determiners and adjectives as well as pronouns. Predicate adjectives are expected to agree with the subject or the object DP they modify in gender, number and case. In terms of finiteness marking, Greek lacks infinitives. Non-finite verb forms include participles, the gerund and the imperative. Finite clauses can be indicative or subjunctive, either of which can serve as complement clauses of verb or noun predicates. Usually, infinitival complements in English are translated into subjunctive clauses in Greek. Further distinctions among subordinate clauses include relatives (subject, object, adjunct), adverbial clauses introduced by connectives (temporal, causal etc.) and complement clauses which include indicative, subjunctive and factive complements, introduced by distinct complementisers (oti, na and pu) respectively (Holton, Mackridge, Philippaki-Warburton \& Spyropoulos, 2012).

\section{Challenges of adapting MAIN to Greek}

The adaptation into Greek began in 2009 during the COST Action IS0804 Language Impairment in a Multilingual Society: Linguistic Patterns and the Road to Assessment which aimed to profile bilingual specific language impairment (biSLI) by establishing a network that 
would coordinate research on the linguistic and cognitive abilities of bilingual children with SLI across different migrant communities (http://bi-sli.org/). Ianthi Tsimpli was one of the two Greek representatives in the Action, while Eleni Peristeri and Maria Andreou were members of the Greek research team. Being part of WG2 which was responsible for developing MAIN under the guidance of Natalia Gagarina and Joel Walters, the Greek adaptation took place in parallel with the design of the original English MAIN (Gagarina et al., 2012) and was piloted several times with monolingual and bilingual typically developing children as well as with monolingual and bilingual children with DLD. This process of developing the narrative texts in different languages in parallel, reduced the challenges of adaptation as phrasing of the text but also of the scoring sheet and the protocol were negotiated across languages. Some challenges were identified in the use and choice of Internal State Terms and the part of speech they belonged to in Greek vs. English. For instance, 'happy', 'angry', 'upset' are participial forms in Greek which include different inflection from adjectives like 'crazy' and 'proud' which are not participles. Physiological terms 'be hungry, thirsty' can be expressed in Greek by a single verb or periphrastically, as in English, through the use of a participle.

Matching syntactic complexity in the Greek and English texts was an objective that required several discussions during the development of the tool. The types of subordination in Greek (specifically the absence of infinitival clauses) and the length of the narrative texts are issues discussed during adaptation. The Greek text was inevitably longer than the English text for reasons to do with richer morphology and longer words as well as syntactic differences such as the obligatorily overt status of complementisers and connectives introducing subordinate clauses in Greek. Finally, the choice of DP, null subject, overt pronoun or object clitic in the narrative text had to be dictated by strategies of reference assignment and appropriateness that are different from English, a language that lacks the null subject option. Presentation of the Greek MAIN included presenting a recorded version, with the whole process of presenting pictures and listening to the stories computerized. This was to ensure that all participants listened to the same prosodic pattern in the story, for the retelling mode. Using a computerized method not only ensured uniformity of presentation but facilitated the assumption of nonshared knowledge of the story between the experimenter and the participant. During the preliminary analysis of the pilot data the comparison between telling and retelling modes in narrative length and microstructure properties revealed better performance for most participants in the retelling mode. This has led to a higher number of retellings published by the Greek researchers as the aim has mainly been to balance the richness of data for both microstructure and macrostructure analyses.

In the next section, an overview of the studies that have been conducted so far with the Greek MAIN is presented.

\section{$4 \quad$ Using the Greek MAIN for research}

All published studies using the Greek MAIN come from the same research team that also undertook the task of tool adaptation (i.e. Ianthi Tsimpli, Maria Andreou, and Eleni Peristeri). 
Narrative elicitation was carried out in both the telling and the retelling mode, while one recent study (Peristeri, Andreou, Tsimpli, \& Durrleman, in press) also addressed children's comprehension performance in the MAIN. We should note that a computerized version of the Greek MAIN (rather than manually unfolding the pictures in pairs of two) was systematically employed across all studies and modes of elicitation.

The first published study to use the LITMUS-MAIN in Greek was conducted by Tsimpli, Peristeri, and Andreou (2016). In this study, 5- to 11-year-old monolingual Greekspeaking and bilingual Albanian-Greek children with and without DLD were tested on both telling and retelling. The study's general objective was to investigate whether bilingualism would confer an advantage in the microstructure and macrostructure of the narrative performance of children with DLD, and also explore story-telling vs. retelling effects on their narrative performance. The pattern of results revealed significant bilingualism effects for DLD children in retelling only. More specifically, both groups with DLD exhibited considerably lower narrative length than TD groups in both telling and retelling, yet, bilingual children with DLD produced higher rates of subordinate clauses and function words than their monolingual peers with DLD in retelling. Regarding macrostructure, retelling was found to boost the use of emotion and mental state terms for bilingual children with DLD relative to monolingual children with DLD, while both bilingual groups with and without DLD obtained higher story structure complexity and comprehension scores than their monolingual peers in retelling. Furthermore, the same study found strong correlations between DLD children's performance in narrative microstructure and macrostructure, and their performance in two language screening tests, namely, expressive vocabulary and sentence repetition.

Andreou, Tsimpli, Kananaj, and Kapia (2016) have also examined narrative mode (telling vs retelling) effects on the use of reference, as well as the microstructure and macrostructure of the narrative production in 6- to 7-year-old TD monolingual Greek-speaking children, age-matched TD monolingual Albanian-speaking children, and a group of TD GreekAlbanian children, who were tested on both languages using MAIN. Retelling was found to improve both micro- and macrostructure in all groups. Specifically, narrative length and numbers of content and function words increased in retelling (vs telling), while structural complexity as a measure of macrostructure was also higher in retelling. Regarding reference use, bilingual children were found to use higher rates of definite NPs to maintain a character in both Greek and Albanian narratives, while both monolingual groups showed a preference for null pronouns for the same function. According to the authors, a possible explanation for this pattern of results might have been Greek-Albanian children's tendency to avoid the production of ambiguous referential expressions by using referentially explicit forms, such as definite DPs.

In a following study, Tsimpli, Peristeri, and Andreou (2017) tested the narrative performance of 7- to 9-year-old Russian-Greek bilingual children with typical development and with DLD. The main objective of the study was to detect language impairment effects in the use of articles and clitics when introducing, reintroducing and maintaining characters, as well as investigate whether the error pattern in article use would be related to the syntactic position of the Determiner Phrases (DP) in the children's narrative production. Children's narratives were elicited in the telling mode using the two stories (i.e. Baby goats and Baby birds) of the 
LITMUS-MAIN. According to the results, both bilingual groups tended to use referentially appropriate forms in Reintroduction. However, the group with DLD exhibited significantly higher rates of article omissions in the Introduction and more inappropriately marked pronominal clitics in Maintenance relative to the TD bilingual group. Also, the syntactic position of the DP appeared to play an important role in the distribution of errors, with subject (vs. object) DPs being more error-prone for both groups of children.

In a recent study, Andreou, Peristeri, and Tsimpli (in press) examined L1 effects in the use of referential expressions to maintain reference to characters in the narratives of 5- to 11year-old Albanian-Greek and Russian-Greek children with DLD, along with TD bilingual groups speaking the same language pairs. The overall results reflect the joint contribution of language impairment and L1-specific typological properties.

In another recent study, Peristeri, Andreou, Tsimpli, and Durrleman (in press) investigated bilingualism effects in the listening comprehension of 6- to 8-year-old monolingual Greek and Albanian-Greek bilingual children with DLD, along with two groups of age-matched TD monolingual Greek and Albanian-Greek bilingual children. Children's narrative comprehension was assessed through retelling, using the Cat and Dog stories of MAIN. Besides narrative comprehension, the children's language ability, updating and Theory-of-Mind/falsebelief attribution skills were also investigated and were entered in the analyses as potential predictors of children's comprehension performance. Bilingual children with and without DLD scored higher in narrative comprehension than their TD and DLD monolingual peers. Similarly, bilingual children with DLD outperformed their monolingual peers with DLD on the Theory of Mind task, though no difference between the two groups was observed in the updating, executive function task. Typically-developing children's narrative comprehension was predicted by their language and executive function performance, while bilingual DLD children's narrative comprehension was predicted by performance on the Theory of Mind task and their dominance in L2/Greek. The overall results of the study indicate advantages for bilingual children with DLD in narrative comprehension and Theory of Mind, suggesting a link between these the two domains.

\section{$5 \quad$ Concluding remarks}

Though the evidence drawn so far from studies using the Greek version of the LITMUS-MAIN suggests that the specific tool represents a promising marker for the clinical features of both monolingual and bilingual children with DLD, its use still remains limited in the Greek academic community. This is probably due to the limited number of norm-referenced tests for the diagnosis of DLD in Greek-speaking children, particularly in the preschool and early school years, as well as the critical gap in standardized testing tools to assess the language abilities of bilingual children in their second language like Albanian, which is the most widely spoken heritage language in Greece. This problem is well known among scientists who conduct research in the field of neurodevelopmental disorders in Greece, as well as public and private clinical services. Future research should attempt to incorporate the Greek version of the MAIN 
tool and disseminate its validity in both the academia and various research settings that take interest in the narrative abilities of children with and without a disorder. To this end, it would be essential to create a digitized version for testing in clinical and non-clinical contexts.

\section{$6 \quad$ References}

Andreou, M., Peristeri, E., \& Tsimpli, I. M. (in press). Reference maintenance in the narratives of Albanian-Greek and Russian-Greek children with Developmental Language Disorder: a study on crosslinguistic effects. First Language (Special Issue: Referentiality in narratives, edited by N. Gagarina \& U. Bohnacker).

Andreou, M., Tsimpli, I. M., Kananaj, A., \& Kapia, E. (2016). Narrative insights from 6-7-year-old GreekAlbanian children. In M. Mattheoudakis and K. Nicolaidis (Eds.), Selected Papers of the $21^{\text {st }}$ International Symposium of Theoretical and Applied Linguistics (pp. 67-82). Thessaloniki: Prothiki Open Access Journals, Aristotle University of Thessaloniki.

Beazidou, E., Botsoglou, K., \& Vlachou, M. (2013). Promoting emotional knowledge: strategies that Greek preschool teachers employ during book reading. Early Child Development and Care, 183(5), 613-626.

Botsas, G. (2017). Differences in Strategy Use in the Reading Comprehension of Narrative and Science Texts among Students with and without Learning Disabilities. ERIC, 15(1), 139-162.

Gagarina, N., Klop, D., Kunnari, S., Tantele, K., Välimaa, T., Balčiūnienė, I., Bohacker, U., \& Walters, J. (2012). MAIN: Multilingual Assessment Instrument for Narratives. ZAS Papers in Linguistics, 56.

Gagarina, N., Klop, D., Kunnari, S., Tantele, K., Välimaa, T., Balčiūnienė, I., Bohnacker, U., \& Walters, J. (2015). Assessment of Narrative Abilities in Bilingual Children. In S. Armon-Lotem, J. de Jong, \& N. Meir (Eds.), Assessing multilingual children: disentangling bilingualism from language impairment (pp. 243-269). Bristol: Multilingual Matters.

Gagarina, N., Klop, D., Kunnari, S., Tantele, K., Välimaa, T., Bohnacker, U. \& Walters, J. (2019). MAIN: Multilingual Assessment Instrument for Narratives - Revised. ZAS Papers in Linguistics, 63.

Holton, D., Mackridge, P., Philippaki-Warburton, I., \& Spyropoulos, V. (2012). Greek: A Comprehensive Grammar of the Language. $2^{\text {nd }}$ Edition. Routledge Comprehensive Grammars.

Peristeri, E., Andreou, M., Tsimpli, I. M., \& Durrleman, S. (in press). Bilingualism effects in the listening comprehension skills of children with Developmental Language Disorder: Associations with formal language, executive functions and Theory of Mind. In U. Bohnacker \& N. Gagarina (Eds.), Developing narrative comprehension: Multilingual Assessment Instrument for Narratives. Amsterdam: John Benjamins.

Tsimpli, I. M., Peristeri, E., \& Andreou, M. (2016). Narrative production in monolingual and bilingual children with Specific Language Impairment. Applied Psycholinguistics, 37(1), 195-216.

Tsimpli, I. M., Peristeri, E., \& Andreou, M. (2017). Cross-linguistic influence meets language impairment: Determiners and Object clitics in bilingual children with typical development and with Specific Language Impairment. In L. Cornips, E. Blom, \& Z. Schaeffer (Eds.), Cross-linguistic influence in bilingualism in Bilingualism: A Festschrift for Aafke Hulk (pp .331-353). Amsterdam: John Benjamins. 